\title{
Protective effects of Camellia sinensis on Syzygium aromaticum- or chlorpyrifos- induced reproductive toxicity in male Wistar rats
}

\author{
Damola V. Akinwande ${ }^{1}$, Joseph A. Adeyemi ${ }^{1 *}$ D, Solomon T. Olawuyi ${ }^{2}$, Busuyi K. Akinola ${ }^{2}$ and Chris O. Adedire ${ }^{1}$
}

\begin{abstract}
Background: The potential toxicity of clove, Syzygium aromaticum, notwithstanding its beneficial health effect to human health remains a critical issue.

Purpose: This study was designed to assess the effects of oil extracts of clove (S. aromaticum) on reproductive parameters in Wistar rats. The ameliorative effect due to co-administration with green tea, Camellia sinensis, was also determined.

Methods: Adult rats were exposed via oral gavage to mineral oil (negative control), $5 \%$ green tea (GT), $12.5 \mathrm{mg} / \mathrm{kg} /$ day chlorpyrifos (CHL, positive control), $360 \mathrm{mg} / \mathrm{kg} /$ day clove oil (CO), green tea + chlorpyrifos (GT+CHL), or green tea + clove oil $(\mathrm{GT}+\mathrm{CO})$ for 3 weeks, after which the animals were sacrificed and the following sperm parameters: total sperm count, sperm motile count, sperm progressive assessment, and sperm morphology were determined. The serum levels of reproductive hormones, testosterone, follicle stimulating hormone (FSH) and luteinizing hormone (LH), were determined. The histological sections of the testes were also performed.

Results: The results revealed that $\mathrm{S}$. aromaticum treatment resulted in significant damage to the sperm morphology especially at the neck and tail regions with only a marginal change to the total sperm count, sperm motile count, and sperm progressive assessment. The levels of testosterone, FSH, and LH decreased significantly in rats treated with S. aromaticum. Histopathological analyses revealed significant disruption of normal testes structure in rats that were treated with either clove oil or chlorpyrifos.
\end{abstract}

Conclusion: Overall, the results of this study show that the co-administration with C. sinensis has the potential to ameliorate the clove-induced reproductive toxicity in rats.

Keywords: Plant-based pesticide, Chlorpyrifos, Syzygium aromaticum, Sperm parameters, Sex hormones, Histopathology

\section{Background}

In recent times, there is strong advocacy for the use of eco-friendly plant-based pesticides as alternatives to the non-eco-friendly synthetic pesticides (Dubey, Srivastava, \& Kumar, 2008; Kedia, Prakash, Mishra, Singh, \& Dubey, 2015). The literature is rich on the toxic effects of synthetic pesticides on man and other living organisms; these toxic effects include developmental impairments,

\footnotetext{
* Correspondence: joseph.adeyemi@gmail.com

'Department of Biology, School of Sciences, Federal University of

Technology, P.M.B. 704, Akure, Ondo State, Nigeria

Full list of author information is available at the end of the article
}

DNA fragmentation, compromised immunity, organ toxicity, endocrine disruption, neuro-degeneration, oxidative stress, and reproductive abnormality (BenAbdallah, Slima, Dammak, Keskes-Ammar, \& Mallek, 2009; Joshi, Mathur, gajraj, \& Sharma, 2003; Sakr, \& Al-Amoudi, 2012). Plant-based pesticides are considered as better alternatives to conventional synthetic pesticides for obvious reasons; they tend to have a broad-spectrum activity, they are humanly safe and biodegradable and are easy to process and use (Dinesh, Kimara, Kumar, \& Das, 2014).

Several plant materials have been reported to possess insecticidal properties. Examples are Azadirachta indica, 
Nicotiana sp, Derris sp, Schoenocaulon officinale, Syzygium aromaticum Clerodendrum infortunatum, Dennettia tripetala, Anchomanes difformis, etc. (Adedire \& Akinkurolere, 2005; Dimetry, 2012; Dinesh et al., 2015; Mikami \& Ventura 2008). In spite of the wide advocacy for their use as pesticides, little is currently known about the potentially toxic effects that may arise from their use. The treatment of albino rats with an aqueous solution of nicotine, a compound derived from Nicotiana tabacum, caused oxidative stress and damage to the liver (BenSaad et al., 2018; Chowanski et al., 2016). Recently, we showed that oil extracts of clove, S. aromaticum also caused oxidative stress and liver damage in male Wistar rats (Adeyemi et al., 2018). These and other studies are evidence of potential toxicity of plant-based pesticides to mammals.

The health benefits of drinking green tea are quite enormous; they include reduced risk of cardiovascular diseases, degenerative diseases, and cancer. Also, green tea has been shown to result in improvement of asthenia, diarrhea, bronchitis, asthma, hyperlipidemia, cellulitis, and abscesses as well as weight reduction (Kao, Chang, Lee, \& Chen, 2006; Shula, 2007; Schönthal, 2011; Wolfram, 2007) . More importantly, green tea has been shown to improve the reproductive health in humans (Ly, Yockell-Lelievre, Ferraro, Arnason, \& Gruslin, 2015; Roshdy et al., 2013). The therapeutic ability of green tea has been closely linked to the presence of polyphenols such as epigallocatechin gallate (EGCG), epigallocatechin (EGC), epicatechin gallate (ECG), epicatechin (EC), catechin gallate, and and gallocatechin gallate (Chen et al., 2003; Harold \& Graham 1992; Henning et al., 2003).

Reproductive impairments such as low sperm counts, damaged sperm and testes, and alteration in hormonal levels are often associated with exposure to synthetic chemical pesticides ( $\mathrm{Hu}$ et al., 2013; $\mathrm{Li}, \mathrm{Pan}, \mathrm{Hu}, \mathrm{Li}$, \& $\mathrm{Xu}, 2013)$, so the likelihood of plant-based pesticides to as well cause reproductive defects is worth investigating. This study is therefore designed to investigate the reproductive toxicity of oil extract of clove, S. aromaticum, in male Wistar rats. The ameliorative effect of green tea, Camellia sinensis was equally investigated.

\section{Materials and methods}

\section{Extraction of essential oils from S. aromaticum}

The essential oil was extracted from clove flower buds following the procedures of Ileke and Ogungbite (2015). Dried flower buds of $S$. aromaticum were obtained from a local market within Akure metropolis and pulverized into a fine powder using a blender. Acetone extracts of $S$. aromaticum were obtained using a cold extraction method. This was done by soaking $100 \mathrm{~g}$ of the powder in an extraction bottle containing $300 \mathrm{ml}$ of acetone.
The mixture was stirred occasionally with a glass rod, and extraction was terminated after $72 \mathrm{~h}$. The extract was filtered through Whatman filter paper (pore size; $0.7 \mu \mathrm{m})$. The extraction solvent was evaporated using a rotary evaporator set at $56{ }^{\circ} \mathrm{C}$. The resulting extract was air-dried in order to remove traces of solvent.

\section{Experimental animals}

Adult male Wistar rats weighing approximately $200 \mathrm{~g}$ were obtained from a commercial farm within Akure metropolis and were placed individually in polypropylene cages, with laboratory grade pine shavings as bedding. Rats were allowed to acclimatize to experimental room conditions for 2 weeks prior to commencement of experiments. Rats were fed with rat chow and tap water ad libitum, throughout the period of the experiment.

\section{Experimental design}

The animals were randomly allocated into six groups ( $n=5$ per group) and were exposed through oral gavages to one of the following treatments: mineral oil (OIL, vehicle for extracted clove oil, thus serving as negative control), $5 \%$ green tea (GT), $12.5 \mathrm{mg} / \mathrm{kg} /$ day chlorpyrifos (CHL, positive control), $360 \mathrm{mg} / \mathrm{kg} /$ day extracted clove oil (CO), green tea + chlorpyrifos $(\mathrm{GT}+\mathrm{CHL})$, and green tea + extracted clove oil $(\mathrm{GT}+\mathrm{CO})$. Experimental treatment was done every day and lasted for 3 weeks. At the end of the third week of treatment, animals were sacrificed using cervical dislocation.

\section{Total sperm count and motility assessment}

The total sperm count and motility assessment were done following the procedure described by Yokoi, Uthus, and Nielsen (2003) with minor modification. The caudal epididymis was removed and minced with surgical blade in $1 \mathrm{ml}$ of normal saline, placed in a rocker for $5-10 \mathrm{~min}$, and incubated at $37^{\circ} \mathrm{C}$ for about $2 \mathrm{~min}$. The solution was diluted 100 -folds with sodium bicarbonate/formalin solution. The total sperm count was done by placing $10 \mu \mathrm{l}$ of the aliquot into the Neuber's counting chamber. The sample was allowed to stand for $5 \mathrm{~min}$ and then observed under the microscope at $x$ 400 magnification. Sperm motility progressive assessment was assessed by placing a drop of the sperm aliquot on the slide, covered with coverslip and then observed under the microscope at $\times 400$ objectives. A sperm was considered motile when it exhibited distinct flagella activity. Sperm motility was determined by assessing at least five microscopic fields to classify 100 spermatozoa. Motile sperms were further categorized into either fast or slow based on recommendations of the WHO (1999). 


\section{Sperm morphology}

The morphology of the spermatozoa was determined on the same sperm dilution that was used for motility assessment using the procedures described by Rezvanfar et al. (2008). In detail, a drop of sperm suspension was added into an equal volume $1 \%$ eosin-y $5 \%$ nigrosin, which was then mixed together and smeared on prewarmed clean glass slides and air-dried. A total of 200 sperm cells were examined at $\times 400$. The morphology of the sperm cells was categorized based on the presence of one or more abnormal features into tail defects (short, irregular, coiled or multiple tail), neck and middle piece defects (distended, irregular, bent middle piece, abnormally thin middle piece), and head defects (round head, small or large size, double or detached head).

\section{Histology of the testis}

The excised testes from the rats were processed for hematoxylin and eosin staining as described by Bancroft and Stevens (1996). The testes were clearly dissected out, sliced, and fixed in neutral buffered $10 \%$ formalin solution for $48 \mathrm{~h}$ after which they were transferred into $70 \%$ ethanol for storage until further histological procedures were performed. Fixed tissues were dehydrated in ascending series of ethanol, cleared in methyl benzoate, and embedded in paraffin wax. About $7-\mu$ m-thick sections of the samples were cut with microtome and stained with hematoxylin and eosin dyes. Sections were later observed under light microscope and photomicrographs were taken.

\section{Determination of serum hormonal levels}

Blood samples were collected into plain bottles through cardiac puncture and were allowed to clot to get the sera. The sera were then pipetted into plain sample bottles and stored at $-20{ }^{\circ} \mathrm{C}$ until assayed for hormonal levels. The levels of testosterone, luteinizing hormone $(\mathrm{LH})$, and follicle-stimulating hormone (FSH) were determined using enzyme-linked immunosorbent assay (ELISA) kits obtained from Cayman Chemical, USA. The assays were performed following the instructions of the manufacturer.

\section{Statistical analysis}

All statistical analyses were performed using Statistical Package for Social Sciences (SPSS version 15.0) software. Analysis of variance (ANOVA) and post hoc tests were used to analyze the data. Tukey's multiple comparisons was used to test for statistically significant difference between control and experimental groups. Results are presented as the mean \pm standard error of mean (SEM). Results were considered significant at $p<0.05$.

\section{Results}

\section{Total sperm count}

The total sperm counts are presented in Fig. 1. The total sperm counts differed significantly among the groups $\left(\mathrm{F}_{5,24}=10.99 ; p<0.0001\right)$. The total sperm count was lowest in the positive control group (CHL) in which the sperm count was $45 \pm 4.47 \times 10^{6}$ while the group that was treated with green tea (GT) had the highest sperm count of $99.80 \pm 6.60 \times 10^{6}$. The animals that were treated with the extract of clove oil had a sperm count of $61.25 \pm 10.08 \times 10^{6}$. The co-administration with green tea resulted in increased total sperm count in the chlorpyrifos $(\mathrm{CHL})$ and the clove oil-treated animals.

\section{Motility assessment}

The motile count differed significantly among the groups $\left(F_{5,24}=9.348 ; p=0.0001\right)$. The motile count was lowest in the positive control group (CHL) in which the motile count was $23 \pm 1.23 \times 10^{6}$ while the group that was treated green tea (GT) exhibited the highest motile count of $75.2 \pm 6.25 \times 10^{6}$. The animals that were treated with the extract of clove oil showed a motile count of $41.25 \pm 10.08 \times 10^{6}$. The co-administration with green tea resulted in increased sperm motility in the chlorpyrifos (CHL) and the clove oil-treated animals (Fig. 2).

\section{Sperm progressive assessment}

The sperm progressive assessment (slow and fast) is presented in Fig. 3. There was a significant difference in the percentage fast $\left(\mathrm{F}_{5,24}=6.119 ; p=0.0014\right)$ and slow $\left(\mathrm{F}_{5,24}=5.556 ; p=0.0019\right)$ sperms among the treatment groups. The percentage of slow sperm was significantly higher in both the positive control (CHL) and the

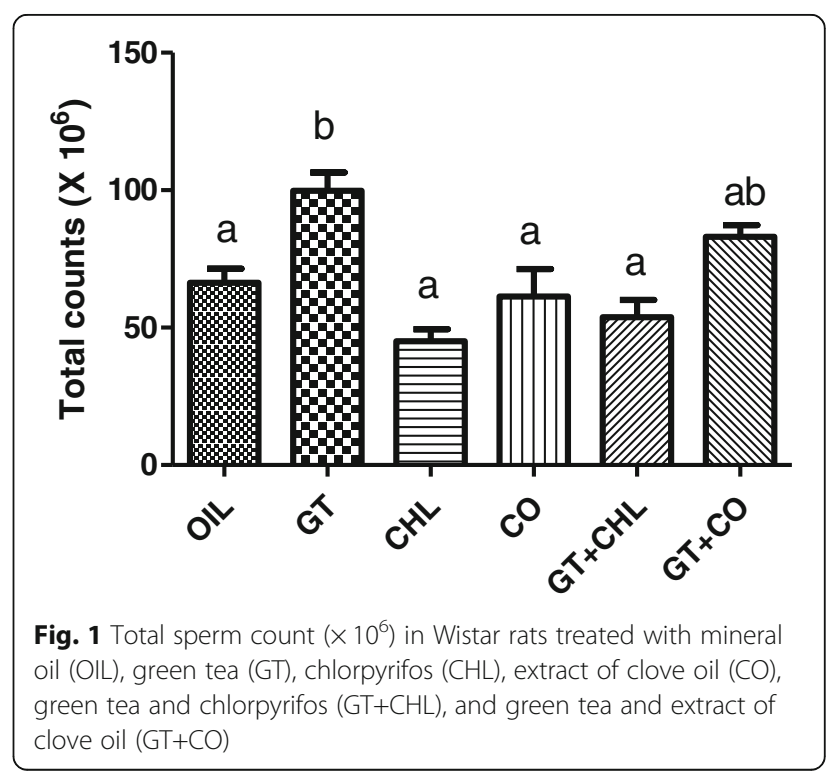




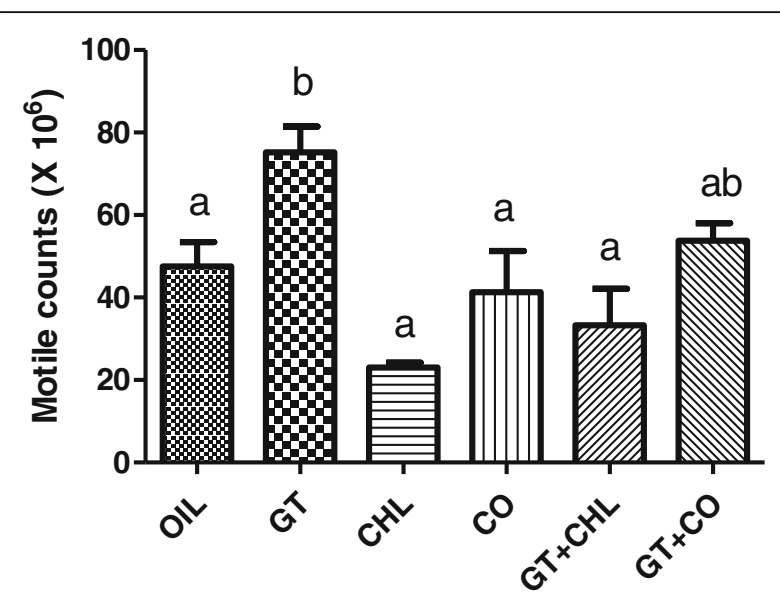

Fig. 2 Sperm motile counts $\left(\times 10^{6}\right)$ in Wistar rats treated with mineral oil (OIL), green tea (GT), chlorpyrifos (CHL), extract of clove oil (CO), green tea and chlorpyrifos ( $\mathrm{GT}+\mathrm{CHL}$ ), and green tea and extract of clove oil $(\mathrm{GT}+\mathrm{CO})$

clove oil-treated animals. The percentage of slow-moving sperms for the positive control (CHL) and the clove oil-treated animals was $68.60 \pm 11.67$ and $53.00 \pm$ 10.16 , respectively. The values for the mineral oil- and green tea-treated groups were $44.20 \pm 3.338$ and $27.00 \pm$ 2.49 , respectively. The co-administration with green tea resulted in an increased number of fast-moving sperms in the chlorpyrifos (CHL) and the clove oil-treated

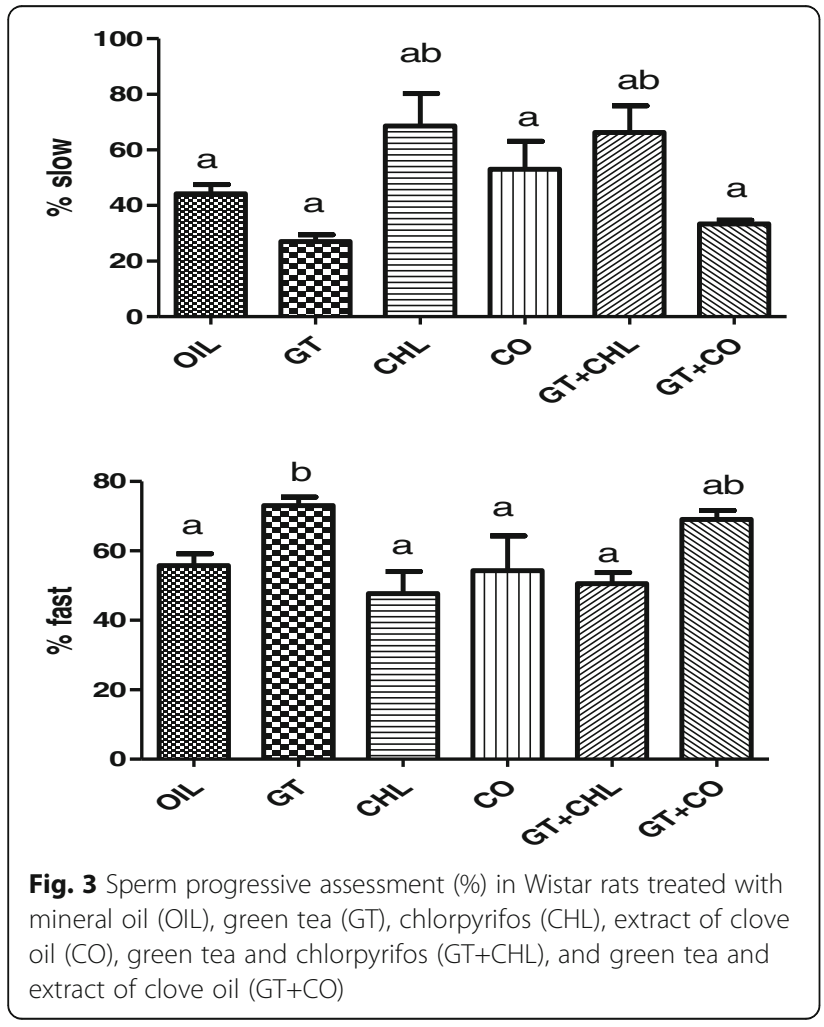

animals especially those that were treated with clove oil and green tea.

\section{Sperm morphology}

The data on sperm morphology were summarized in Fig. 4. The percentage of sperm with normal morphology was significantly higher $(p<0.05)$ in the green tea- and mineral oil-treated animals in comparison with those treated with clove oil or chlorpyrifos or those that received coadministration $\left(\mathrm{F}_{5,24}=6.757 ; p=0.0005\right)$. The percentage of sperm with normal physiology in mineral oil- and green tea-treated groups was $56.20 \pm 5.652$ and $73.40 \pm 2.676$, respectively, while the percentage in those that were treated with clove oil and chlorpyrifos were $46.20 \pm 9.378$ and $27.20 \pm 11.04$, respectively.

The co-administration with green tea resulted in increased percentages of sperms with normal morphology in the chlorpyrifos (CHL) and the clove oil-treated animals. The percentage of sperm with tail deformity morphology was significantly $(p<0.05)$ lower in the green tea- and mineral oil-treated animals in comparison with those treated with clove oil or chlorpyrifos or those that received the co-administration treatment $\left(\mathrm{F}_{5,24}=10.95\right.$; $p<0.0001)$. The percentage of sperms with tail deformity was $9.60 \pm 1.939,17.67 \pm 1.453,22.25 \pm 3.425$, $32.25 \pm 4.029,26.25 \pm 2.394$, and $14.40 \pm 1.122$ for GT, $\mathrm{OIL}, \mathrm{CO}, \mathrm{CHL}, \mathrm{GT}+\mathrm{CHL}$, and $\mathrm{GT}+\mathrm{CO}$, respectively.

The percentage of sperm with neck deformity was significantly lower in the green tea-and mineral oil-treated animals in comparison with those treated with clove oil or chlorpyrifos or those that received the co-administration treatment $\left(\mathrm{F}_{5,24}=6.067 ; p=0.0010\right)$. The percentage of sperm with head deformity was significantly lower $(p<0.05)$ in the green tea- and mineral oil-treated animals in comparison with those treated with clove oil or chlorpyrifos or those that received the co-administration treatment $\left(\mathrm{F}_{5,24}=4.336 ; p=0.0063\right)$.

\section{Serum hormonal levels}

The serum testosterone levels decreased significantly ( $p$ $<0.05)$ in rats that were treated with chlorpyrifos and clove oil in comparison to those treated with green tea, mineral oil, or the co-administration treatment $\left(\mathrm{F}_{5,24}=\right.$ 6.442; $p=0.0010)$. The levels of testosterone for the positive control $(\mathrm{CHL})$ and the clove oil-treated animals were $0.0638 \pm 0.0119$ and $0.1194 \pm 0.0222 \mathrm{ng} / \mathrm{ml} \mathrm{re}-$ spectively. The values for the mineral oil- and green teatreated groups were $0.1586 \pm 0.0155$ and $0.2005 \pm$ $0.0178 \mathrm{ng} / \mathrm{ml}$ respectively. The co-administration with green tea increased the levels of testosterone in the chlorpyrifos (CHL) and the clove oil-treated animals. The levels of follicle stimulating hormone (FSH) differed significantly among the groups $\left(\mathrm{F}_{5,24}=153 ; p<0.0010\right)$. The levels of follicle stimulating hormone (FSH) were 

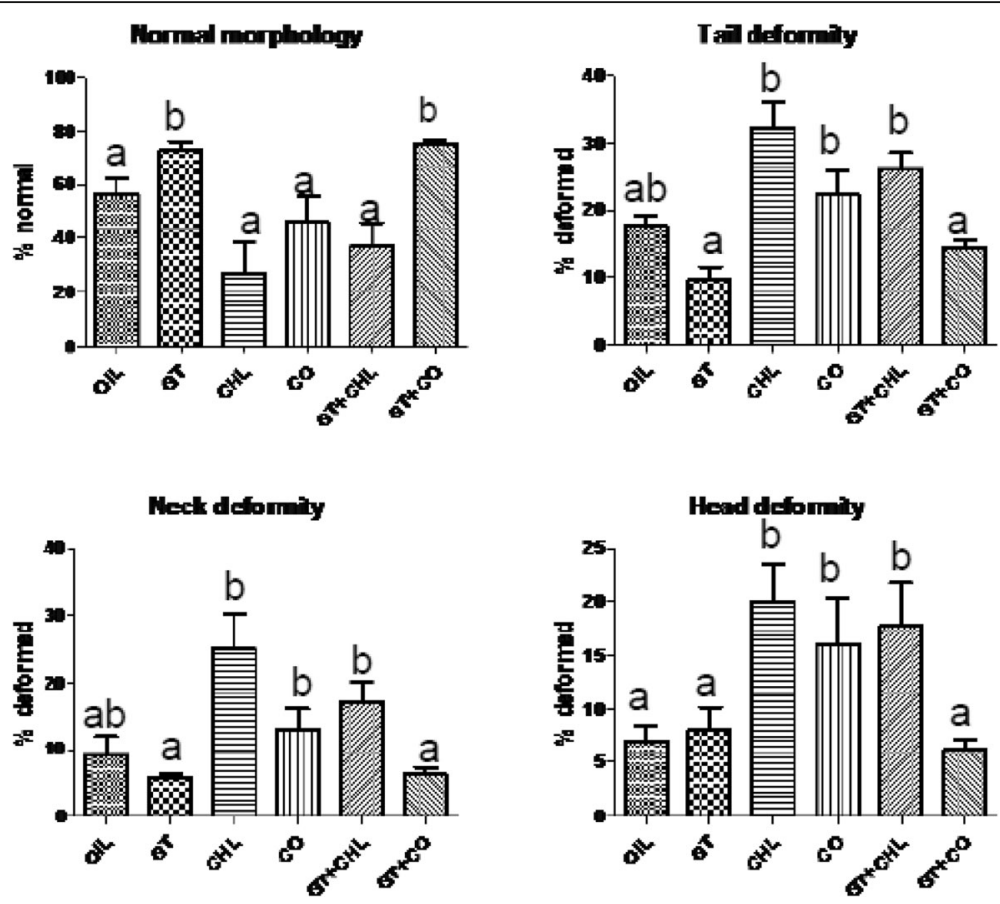

Fig. 4 Sperm deformity (\%) in Wistar rats treated with mineral oil (OIL), green tea (GT), chlorpyrifos (CHL), extract of clove oil (CO), green tea and chlorpyrifos $(\mathrm{GT}+\mathrm{CHL})$, and green tea and extract of clove oil $(\mathrm{GT}+\mathrm{CO})$

$9.824 \pm 0.560,2.748 \pm 0.328,1.678 \pm 0.1295,1.018 \pm$ $0.1245,6.284 \pm 0.1636$, and $1.238 \pm 0.0963 \mu \mathrm{g} / \mathrm{ml}$ for $\mathrm{GT}$, OIL, CO, CHL, GT+CHL, and GT+CO, respectively. The levels of luteinizing hormone $(\mathrm{LH})$ differed significantly among the groups $\left(\mathrm{F}_{5,24}=98.31 ; p<0.0010\right)$. The levels of luteinizing hormone $(\mathrm{LH})$ were $7.586 \pm 0.5614,1.544 \pm$ $0.08548,1.404 \pm 0.1463,0.7560 \pm 0.1282,4.656 \pm 0.2902$, and $1.062 \pm 0.0887 \mu \mathrm{g} / \mathrm{ml}$ for GT, OIL, CO, CHL, $\mathrm{GT}+\mathrm{CHL}$, and $\mathrm{GT}+\mathrm{CO}$, respectively (Fig. 5).

\section{Histology of testes}

The changes in the histological sections of the testes were summarized in Table 1 and shown in Plate 1. Overall, there was no obvious damage to the seminiferous tubules of the testes in rat groups that were treated with mineral oil, green tea, green tea + chlorpyrifos, and green tea + clove oil. However, the structural architecture of the testes was disrupted in rats that were treated with chlorpyrifos and extracts of clove oil. The observed histological changes included loss of both the cellular and tubular constituents of the seminiferous tubules, derangement of the seminiferous tubules, infiltration of fats, and outright loss of the seminiferous tubules.

\section{Discussion}

The present study investigated the potential spermicidal effects of oil extract of clove and chlorpyrifos on male Wistar rats and the ameliorating effect of the green tea. Results did show that both the clove oil and chlorpyrifos had adverse effects on certain sperm parameters like motility, total sperm count, and sperm progressive assessments. The decreased sperm count in rats that were treated with oil extract of $S$. aromaticum could be an indication that this plant material has the potential to alter the processes of spermatogenesis by evoking either hormonal imbalance or damage to important testicular cells such as Sertoli cells (Bretveld, Brouwers, Ebisch, \& Roeleveld, 2007; Mehrpour, Karrari, Zamani, Tsatsakis, \& Abdollahi, 2014). ATP is the energy currency of the cell and very important to cellular activities including motility. The decrease in sperm motility and viability in rats that were treated with extracts of clove oil and chlorpyrifos may be due to non-availability of adenosine triphosphate (ATP) for metabolism as a result of damage of sperm plasma membrane architecture by clove oil and chlorpyrifos (Chaki \& Misro, 2002; Chaudhury, Bhattacharyya, \& Guha, 2004). Similarly, the morphological analyses of sperm revealed that rats that were treated with clove oil or chlorpyrifos had a higher frequency of sperm abnormalities especially at the tail and neck regions. Although the mechanistic explanations for these abnormalities are conjectural, however, the abnormalities could have been due to abnormal chromosome, minor alteration in testicular DNA, or errors during the process of spermatogenesis (Giri, Prasad, Giri, \& Sharma, 2002; Otitoloju, Obe, Adewale, Otubanjo, \& Osunkalu, 2010).

Aside from sperm parameters, hormonal assays quantifying the levels of important hormones such as testosterone, 


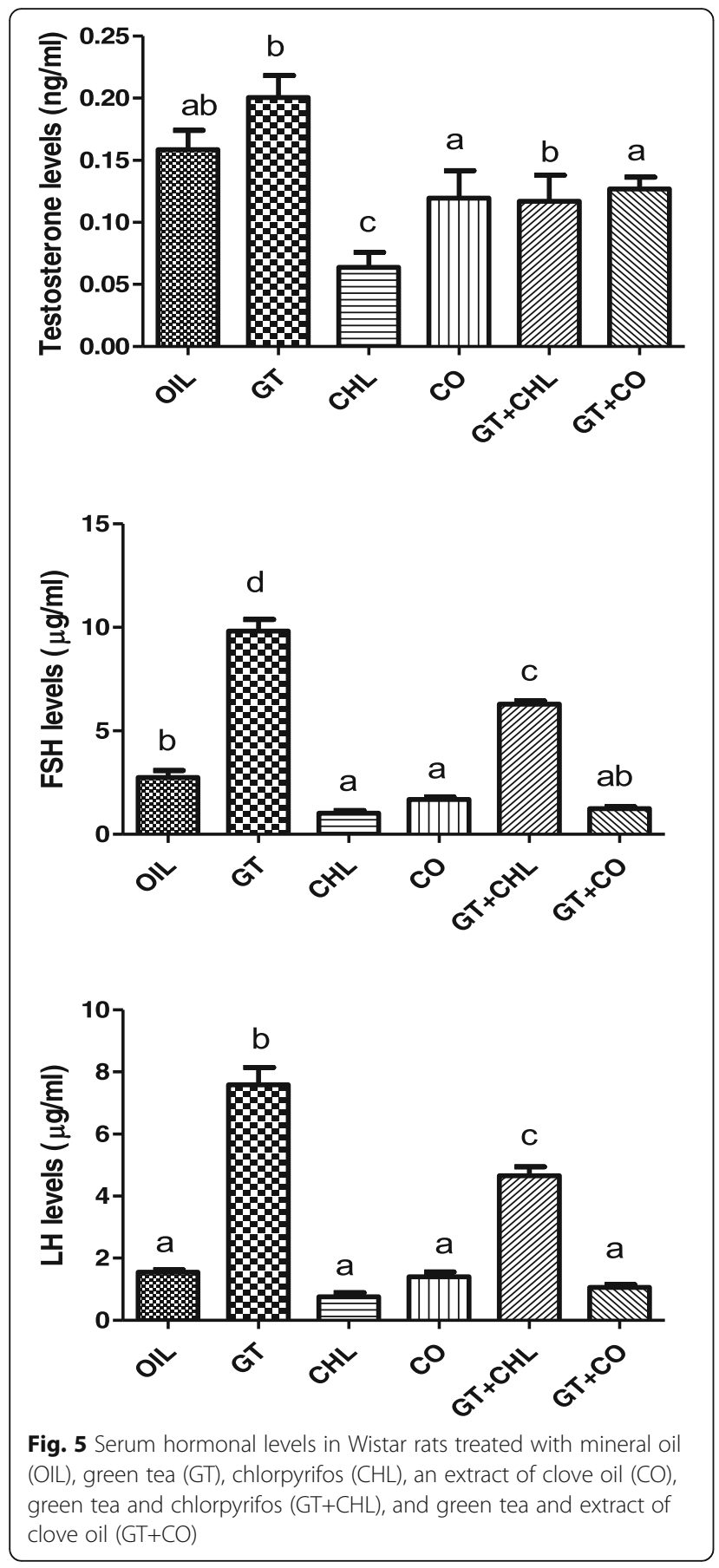

FSH, and LH are useful biomarkers in reproductive toxicology (Rockett \& Kim, 2005). In the present study, the serum levels of testosterone, FSH, and LH were significantly lower in the rats that were treated with clove oil and chlorpyrifos in comparison to other treatment groups. Since these hormones play important roles in the process of spermatogenesis, rats with reduced level of these hormones are prone to developing abnormal sperm and also reduced sexual activity. This could explain the reason for a higher frequency of abnormal sperm in rats that were treated with clove oil and chlorpyrifos (Bretveld, Brouwers, Ebisch, \& Roeleveld, 2007; Mehrpour, Karrari, Zamani, Tsatsakis, \& Abdollahi, 2014).

The reproductive toxicity of clove oil and chlorpyrifos was further substantiated by histopathological analysis of the testes. The treatment of Wistar rats with clove oil and chlorpyrifos resulted in disruption of the normal architecture of the testes, e.g., loss of both the cellular and tubular constituents of the seminiferous tubules, derangement of the seminiferous tubules, fatty infiltration, and outright loss of the seminiferous tubules. The results of this study are consistent with the findings of Sebastian and Raghavan (2015) in which Wistar rats that were exposed to endosulfan, an organochlorine pesticide developed testicular atrophies. Similarly, Joshi, Mathur, and Gulati (2007) in another but similar study also reported that the treatment of Wistar rats with chlorpyrifos for 30 days at various dosage levels caused degenerated seminiferous tubule having decreased number of spermatogenic elements in exposed rats. The loss of cells of the seminiferous tubules in rats that were exposed to clove oil and chlorpyrifos could have been due to increased induction of reactive oxygen species leading to apoptosis in the testicular cells (Sebastian \& Raghavan, 2015).

In this study, the potential of green tea to ameliorate the reproductive toxicity induced by clove oil and chlorpyrifos was investigated since there are reports that green tea has the potential to improve the fertility of male rats (Abdelrazek, Helmy, Elsayed, Ebaid, \& Mohamed, 2016; Ghafurniyan, Azania, Nabiuni, \& Karimzadeh, 2015). The data from the present study supported the assertion that treatment of rats with extracts of green tea has the potential to improve the reproductive fitness of rats. The rats treated with extracts of green tea either alone or in combination with clove oil or chlorpyrifos had higher total and motile sperm counts, the percentage of fast sperm was higher and the frequency of deformed sperms was low compared to the groups that were treated with clove oil or chlorpyrifos. Also, the serum levels of reproductive hormones were higher in rats that were treated with extracts of green tea either alone or in combination with clove oil or chlorpyrifos.

The mechanisms through which the green tea performs these functions are still speculatory but its antioxidant properties may be involved. One of the proposed mechanisms through which the sperm quality in stressed organisms could be compromised is oxidative stress through excessive production of reactive oxygen species (Sanocka \& Kurpisz, 2004; Schulte, Ohl, Sigman, \& Smith, 2010). Green tea possesses a good number of antioxidant compounds such as catechin which has the potential to inactivate free radicals (Al-Wafai, 2013; Burits and Bucar, 2000). 
Table 1 Histological changes in testes of Wistar rats

\begin{tabular}{lcccccc}
\hline Histological signs & Oil & GT & CHL & CO & GT+CHL & GT+CO \\
\hline Normal seminiferous tubules & + & + & - & - & + & + \\
Loss of cellular constituents & - & - & + & + & - & - \\
Loss of tubular constituents & - & - & + & + & - & - \\
Derangement of seminiferous tubules & - & - & + & + & - & - \\
Loss of seminiferous tubules & - & - & + & - & - & - \\
Fatty infilteration & - & - & + & + & - & - \\
\hline Legends: & No & & & & & \\
\hline
\end{tabular}

\section{Conclusion}

In conclusion, the data obtained from this study showed that $S$. aromaticum significantly affected the sperm morphology: a higher percentage of tail-, neck- and head-deformed sperms in rats while the effects on sperm total counts, sperm motile counts, and sperm progressive assessment were merely marginal. Also, hormonal assays showed that $S$. aromaticum has the tendency to cause hormonal imbalance in rats. The histopathological analyses of sections of the testes of stressed rats revealed apparent damage to the structure of the testes; loss of tubular and cellular constituents, fatty infiltration, derangement of seminiferous tubules, etc. The treatment of rats with $C$. sinensis alone or in combination with $S$. aromaticum resulted in improved sperm parameters: higher sperm total counts, sperm motile counts,
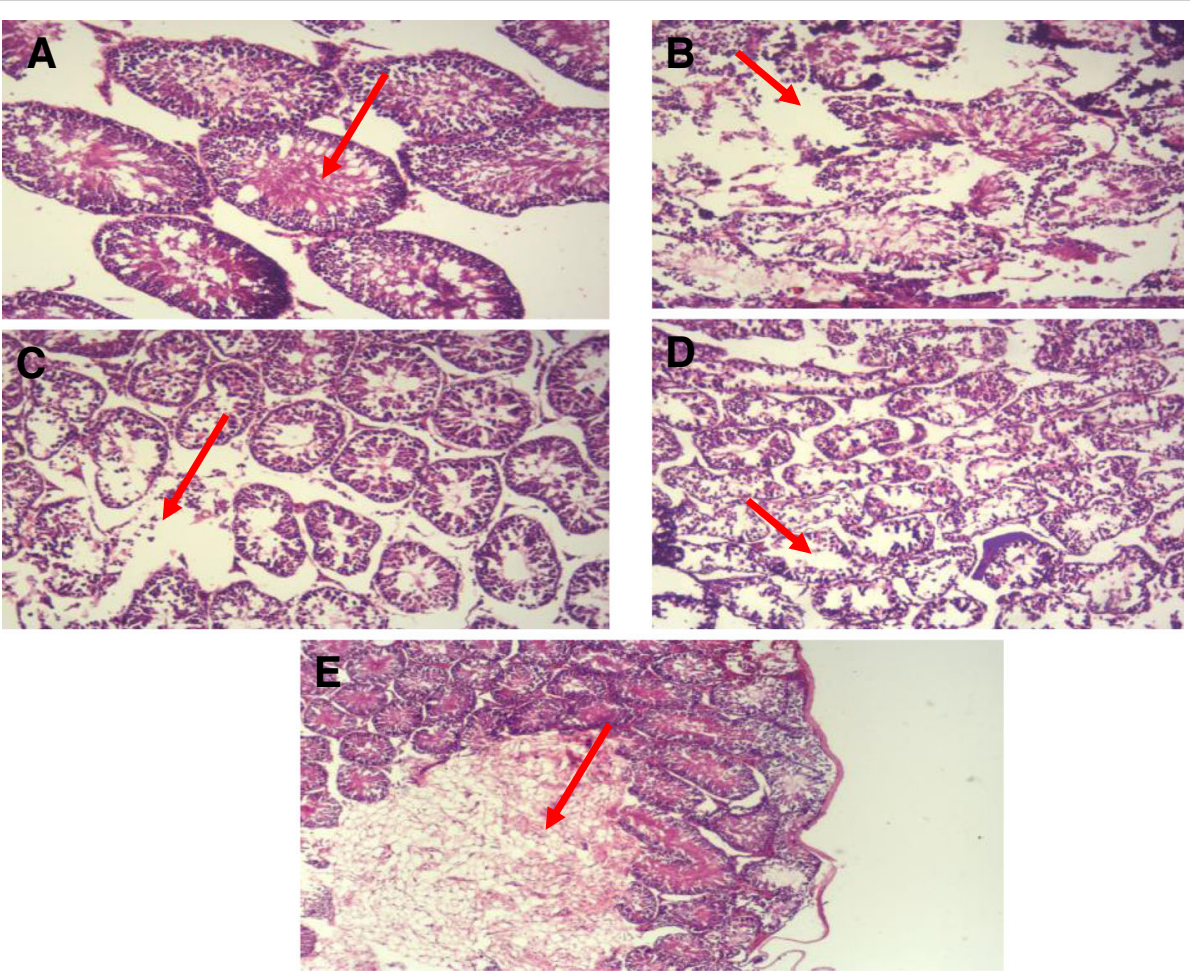

Plate 1 Representative micrograph of sections through the testes of Wistar rats showing A) normal structure of seminiferous tubules, B) loss of tubular constituents of seminiferous tubules, C) derangement of seminiferous tubules, D) loss of cellular constituents of seminiferous tubules, and E) fatty infiltration of seminiferous tubules 
higher percentage fast sperm, less percentage deformed sperms, higher levels of reproductive hormones, and less damage to the testes. From the foregoing, S. aromaticum is potentially toxic to mammals; caution must, therefore, be applied to ensure that a low level of the plant material was used as a pesticide to avoid potential negative effects on mammals.

\section{Abbreviations}

ANOVA: Analysis of variance; LH: Luteinizing hormone; FSH: Follicle stimulating hormone; ELISA: Enzyme-linked immunosorbent assay; ATP: Adenosine triphosphate; SEM: Standard error of the mean

\section{Acknowledgments}

The authors declare that there is no source of funding to be acknowledged.

\section{Authors' contributions}

The authors JAA and COA designed the study. DVA, STO, and BKA performed the experiments. JAA and STO performed the statistical analysis of the data. DVA and BKA wrote the draft of the manuscript. JAA and COA edited the final draft of the manuscript. All authors approved the final draft of the manuscript.

\section{Funding}

Not funded

\section{Availability of data and materials}

All data sets, on which the conclusions of the manuscript rely on, are present in the results section in the manuscript.

\section{Ethics approval}

The experimental procedures were in conformity with national and international standards on the use of laboratory animals. Also, the study was approved by institutional committee on the care and use of animal for experiments

\section{Consent for publication}

Not applicable.

\section{Competing interests}

The authors declare that they have no competing interests.

\section{Author details}

${ }^{1}$ Department of Biology, School of Sciences, Federal University of Technology, P.M.B. 704, Akure, Ondo State, Nigeria. ${ }^{2}$ Department of Anatomy, School of Health Sciences, Federal University of Technology, P.M.B. 704, Akure, Ondo State, Nigeria.

Received: 11 April 2019 Accepted: 14 June 2019

Published online: 04 July 2019

\section{References}

Abdelrazek, H. M. A., Helmy, S. A., Elsayed, D. H., Ebaid, H. M., \& Mohamed, R. M. (2016). Ameliorating effects of green tea extract on cadmium induced reproductive injury in male Wistar rats with respect to androgen receptors and caspase-3. Reproductive Biology, 16, 300-308.

Adedire, C. O., \& Akinkurolere, R. O. (2005). Bioactivity of four plant extracts on coleopterous pests of stored cereals and grain legumes in Nigeria. Zoological Research, 26, 243-249.

Adeyemi, J. A., Arowolo, O. K., Olawuyi, S. T., Alegbeleye, D., Ogunleye, A., Bamidele, O. S., \& Adedire, C. O. (2018). Effect of co-administration of green tea (Camellia sinensis) on clove- (Syzygium aromaticum) induced hepatotoxicity and oxidative stress in Wistar rats. Indian Journal of Physiology and Pharmacology, 62, 195-201.

Al-Wafai, R. J. (2013). Nigella sativa and thymoquinone suppress cyclooxygenase-2 and oxidative stress in pancreatic tissue of streptozotocin-induced diabetic rats. Pancreas, 42, 841-849.

Bancroft, J.D. \& Stevens, A. (1996). The haematoxylin and eosin: theory and practice of histological techniques. 4th ed, Churchill, Livingstone.
BenAbdallah, F., Slima, A. B., Dammak, I., Keskes-Ammar, L., \& Mallek, Z. (2009). Comparative effects of dimethoate and deltamethrin on reproductive system in male mice. Andrologia, 42, 182-186.

BenSaad, A., Rjeibi, I., Alimi, H., Ncib, S., Bouhamda, T., \& Zouari, N. (2018). Protective effects of Mentha spicata against nicotine-induced toxicity in liver and erythrocytes of Wistar rats. Applied Physiology, Nutrition, and Metabolism, 43, 77-83.

Bretveld, R., Brouwers, M., Ebisch, I., \& Roeleveld, N. (2007). Influence of pesticides on male fertility. Scandinavian Journal of Work, Environment and Health, 33, 13-28.

Burits, M., \& Bucar, F. (2000). Antioxidant activity of Nigella sativa essential oil. Phytotherapy Research, 14, 323-328.

Chaki, S. P., \& Misro, M. M. (2002). Assessment of human sperm function after hydrogen peroxide exposure: development of a vaginal contraceptive. Contraception, 66, 187-192.

Chaudhury, K., Bhattacharyya, A. K., \& Guha, S. K. (2004). Studies on the membrane integrity of human sperm treated with a new injectable male contraceptive. Human Reproduction, 19, 1826-1830.

Chen, C. N., Liang, C. M., Lai, J. R., Tsai, Y. J., Tsay, J. S., \& Lin, J. K. (2003). Capillary electrophoretic determination of theanine, caffeine, and catechins in fresh tea leaves and oolong tea and their effects on rat neurosphere adhesion and migration. Journal of Agricultural and Food Chemistry, 51, 7495-7503.

Chowanski, S., Adamski, Z., Marciniak, P., Rosinski, G., Buyukguzel, E. Buyukguzel, K., et al. (2016). A review of bioinsecticidal activity of solanaceae alkaloids. Toxins, 8, 60.

Dimetry, N. Z. (2012). Prospects of botanical pesticides for the future in integrated pest management programme (IPM) with special reference to neem uses in Egypt. Archives of Phytopathology and Plant Protection, 45, 1138-1161.

Dinesh, D. S., Kimara, S., Kumar, V., \& Das, P. (2014). The potentiality of botanicals and their products as an alternative to chemical insecticides to sandflies (Diptera: Psychodidae): A review. Journal of Vector Borne Diseases, 51, 1-7.

Dinesh, D. S., Kumari, S., Pandit, V., Kumar, J., Kumari, N., Hassa, F., et al. (2015). Insecticidal effect of plant extracts on Phlebotomus argentipes (Diptera: Psychodidae) in Bihar, India. Indian Journal of Medical Research, 142, S95-S100.

Dubey, N. K., Srivastava, B., \& Kumar, A. (2008). Current status of plant products as botanical pesticides in storage pest management. Journal of Biopesticides, 1, 182-186.

Ghafurniyan, H., Azania, M., Nabiuni, M., \& Karimzadeh, L. (2015). The effect of green tea extract on reproductive improvement in estradiol valerate-induced polycystic ovarian syndrome in rat. Iranian Journal of Pharmaceutical Research, 14, 1215-1233.

Giri, S., Prasad, S. B., Giri, A., \& Sharma, G. D. (2002). Genotoxic effect of malathion: an organophosphorus insecticide, using three mammalian bioassays in vivo. Mutation Research, 514, 223-231.

Harold, N., \& Graham, P. (1992). Green tea composition, consumption and polyphenol chemistry. Preventive Medicine, 21, 334-350.

Henning, S. M., Fajardo-Lira, C., Lee, H. W., Youssefian, A. A., Go, V. L., \& Heber, D. (2003). Catechin content of 18 teas and a green tea extract supplement correlated with the antioxidant capacity. Nutrition and Cancer, 45, 226-235.

Hu, J., Li, Y., Li, J., Pan, C., He, Z., Dong, H., et al. (2013). Toxic effects of cypermethrin on the male reproductive system: with emphasis on the androgen receptor. Journal of Applied Toxicology, 33, 576-585.

lleke, K. D., \& Ogungbite, O. C. (2015). Alstonia boonei De Wild oil extract in the management of mosquito (Anopheles gambiae), a vector of malaria disease. Journal of Coastal Life Medicine, 3, 557-563.

Joshi, S. C., Mathur, R., Gajraj, A., \& Sharma, T. (2003). Influence of methyl parathion on reproductive parameters in male rats. Environmental Toxicology and Pharmacology, 14, 91-98.

Joshi, S. C., Mathur, R., \& Gulati, N. (2007). Testicular toxicity of chlorpyrifos (an organophosphate pesticide) in albino rat. Toxicology and Industrial Health, 23, 439-444.

Kao, Y. H., Chang, H. H., Lee, M. J., \& Chen, C. L. (2006). Tea, obesity, and diabetes. Molecular Nutrition and Food Research, 50, 188-210.

Kedia, A., Prakash, B., Mishra, P. K., Singh, P., \& Dubey, N. K. (2015). Botanicals as eco friendly biorational alternatives of synthetic pesticides against Callosobruchus spp. (Coleoptera: Bruchidae) - a review. Journal of Food Science and Technology, 52, 1239-1257.

Li, Y. F., Pan, C., Hu, J., Li, J. L., \& Xu, C. (2013). Effects of cypermethrin on male reproductive system in adult rats. Biomedical and Environmental Sciences, 26, 201-208. 
Ly, C., Yockell-Lelievre, J., Ferraro, Z. M., Arnason, J. T., \& Gruslin, J. F. A. (2015). The effects of dietary polyphenols on reproductive health and early development. Human Reproduction Update, 21, 228-248.

Mehrpour, O., Karrari, P., Zamani, N., Tsatsakis, A. M., \& Abdollahi, M. (2014). Occupational exposure to pesticides and consequences on male semen and fertility: a review. Toxicology Letters, 230, 146-156.

Mikami, A. Y., \& Ventura, M. U. (2008). Repellent, antifeedant and insecticidal effects of neem oil on Microtheca punctigera. Brazilian Archives of Biology and Technology, 51, 1121-1126.

Otitoloju, A. A., Obe, I. A., Adewale, O. A., Otubanjo, O. A., \& Osunkalu, V. O. (2010), Preliminary study on the reduction of sperm head abnormalities in mice, Mus musculus, exposed to radiofrequency radiations from global system for mobile communication base stations. Bulletin of Environmental Contamination and Toxicology, 84, 51-54.

Rezvanfar, M. A., Sadrkhanlou, R. A., Ahmadi, A., Shojael-sadee, H., Mohammadirad, A., Salehnia, A., et al. (2008). Protection of cyclophosphamide-induced toxicity in reproductive tract histology, sperm characteristics, and DNA damage by an herbal source; evidence for role of free-radical toxic stress. Human and Experimental Toxicology, 27, 901-910.

Rockett, J. C., \& Kim, S. J. (2005). Biomarkers of reproductive toxicity. Cancer Biomarkers, 1, 93-108.

Roshdy, E., Rajaratnam, V., Maitra, S., Sabry, M., Allah, A. S. A., \& Al-Hendy, A. (2013). Treatment of symptomatic uterine fibroids with green tea extract: a pilot randomized controlled clinical study. International Journal of Women's Health, 5, 477-486.

Sakr, S. A., \& Al-Amoudi, W. M. (2012). Effect of ginger extract on deltamethrin induced histomorphological and immunohistochemical changes in testes of albino rats. Life Science Journal, 9, 771-777.

Sanocka, D., \& Kurpisz, M. (2004). Reactive oxygen species and sperm cells. Reproductive Biology and Endocrinology, 2, 12

Schönthal, A. H. (2011). Adverse effects of concentrated green tea extracts. Molecular Nutrition and Food Research, 55, 874-885.

Schulte, R. T., Ohl, D. A., Sigman, M., \& Smith, G. D. (2010). Sperm DNA damage in male infertility: etiologies, assays, and outcomes. Journal of Assisted Reproduction and Genetics, 27, 3-12.

Sebastian, R., \& Raghavan, S. C. (2015). Endosulfan induces male infertility. Cell Death and Disease, 6, e2022.

Shula, Y. (2007). Tea and cancer chemoprevention: a comprehensive review. Asian Pacific Journal of Cancer Prevention, 8, 155-166.

Wolfram, S. (2007). Effects of green tea and E GCG on cardiovascular and metabolic health. Journal of American College of Nutrition, 26, 3735-388S.

World Health Organization (1999). WHO laboratory manual for the examination of human semen and sperm-cervical mucus interaction, (4th ed., ). Cambridge, UK: Cambridge University Press. 138 pp.

Yokoi, K., Uthus, E. O., \& Nielsen, F. H. (2003). Nickel deficiency diminishes sperm quantity and movement in rats. Biological Trace Element Research, 93, 141-153.

\section{Publisher's Note}

Springer Nature remains neutral with regard to jurisdictional claims in published maps and institutional affiliations.

\section{Submit your manuscript to a SpringerOpen ${ }^{\circ}$ journal and benefit from:}

- Convenient online submission

- Rigorous peer review

- Open access: articles freely available online

- High visibility within the field

- Retaining the copyright to your article

Submit your next manuscript at $\boldsymbol{\nabla}$ springeropen.com 